\title{
Borrando as fronteiras do audiovisual: o pensamento crítico sobre as imagens em múltiplas mídias
}

\section{Blurring the borders of audiovisual: thinking critically about images on multiple media}

Sofia Franco Guilherme ${ }^{1}$ 


\section{Resumo}

Resenha do livro MUANIS, F. C. Convergências audiovisuais: linguagens e dispositivos. Curitiba: Appris, 2020.

Palavras-chave

Audiovisual, mídia, convergência, linguagem, comunicação.

Abstract

Review of the book MUANIS, F. C. Convergências audiovisuais: linguagens e dispositivos. Curitiba: Appris, 2020.

Keywords

Audiovisual, media, convergence, language, communication. 


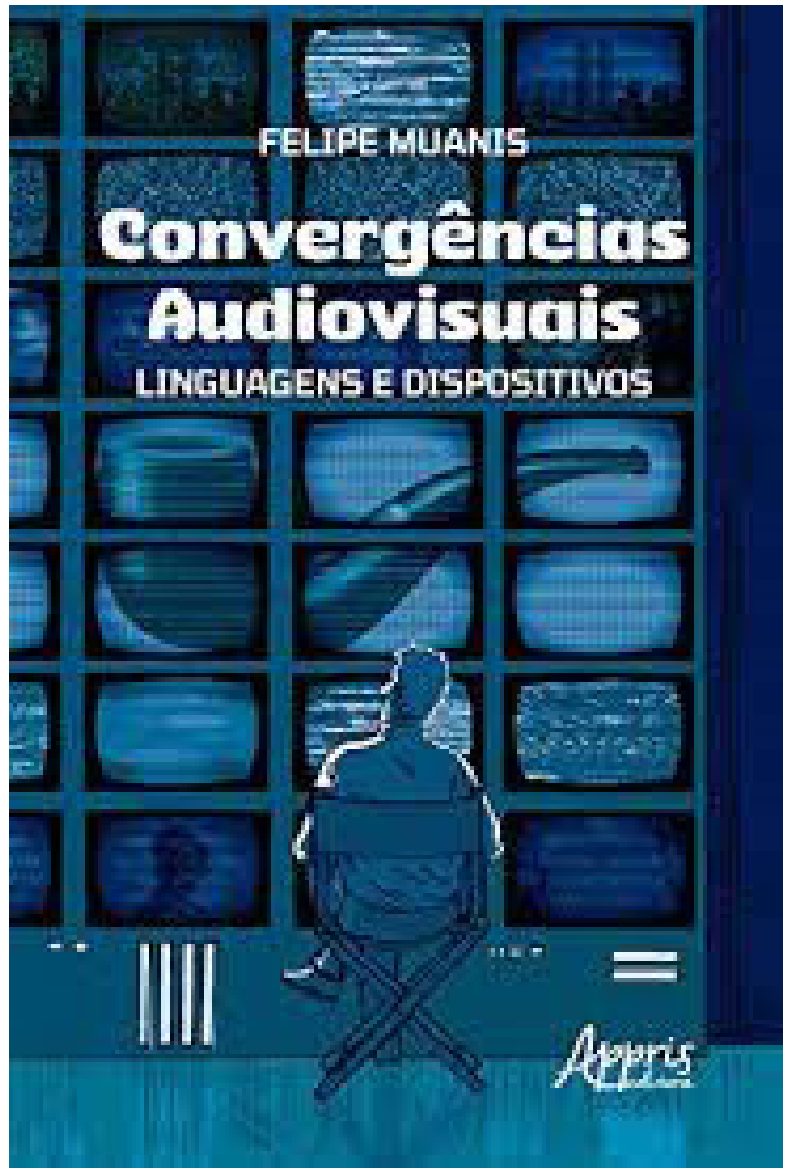

As imagens televisuais e digitais se tornaram, especialmente no fim do século XX e início do XXI, parte fundamental da cultura e permeiam diversos aspectos da vida cotidiana na contemporaneidade. Rodowick (1995) propõe a cultura audiovisual como uma mudança histórica de paradigma produzida pelo surgimento de novas tecnologias de comunicação digital na sociedade. Essas tecnologias promovem a convergência midiática e novas formas de transmissão de informação. Desta maneira, é necessário desenvolvermos um pensamento interdisciplinar na investigação das transformações na comunicação, nos modos de representação e na produção, circulação e leitura de signos neste ecossistema multimidiático.

O livro de Felipe Muanis, Convergências audiovisuais: linguagens e dispositivos, está inserido neste contexto cultural e investiga o audiovisual produzido em múltiplas plataformas e suportes, da televisão ao cinema e à internet, seus diversos gêneros e suas relações com outras mídias e linguagens. A coletânea de textos escritos ao longo dos últimos anos estabelece diálogos transversais sobre questões estéticas, 
éticas e políticas de obras audiovisuais por meio da análise de objetos distintos, enfrentando os desafios da pesquisa que se dedica a pensar sobre a pluralidade e as imbricações dos meios de comunicação na contemporaneidade.

Os 19 capítulos do livro podem ser divididos em blocos temáticos, como apontado pelo autor na apresentação da obra. O primeiro conjunto de textos volta-se às "demandas e urgências da televisão, em diálogo direta ou indiretamente com a realidade brasileira do audiovisual" (p. 14). No bloco seguinte, os textos exploram as fronteiras entre as imagens televisivas e o cinema, analisando as relações entre objetos destes dois meios entre si e também com a literatura e outras linguagens artísticas. Na parte final do livro, os capítulos se debruçam sobre as expressões do documentário, buscando expandir os limites por meio da análise de objetos em diversos suportes.

Com esta organização, fica claro o objetivo do autor ao reunir este conjunto de textos em um único volume, reforçando a fluidez das fronteiras entre os variados produtos audiovisuais encontrados:

\footnotetext{
Cada vez mais torna-se difícil discutir audiovisual e seus objetos isoladamente, e o eixo condutor desta pesquisa é justamente um foco nesses entrelugares, nos espaços imprecisos em que se mesclam e que devem ser considerados para uma definição do campo audiovisual contemporâneo em suas mais diversas manifestações, seja do cinema para televisão, passando pela literatura, pelas vídeoinstalações e projeções mapeadas. (MUANIS, 2020, p. 17)
}

Destacamos a proposta feita por Muanis no primeiro capítulo de uma alfabetização audiovisual para o desenvolvimento do senso crítico sobre o que se assiste. De acordo com esta perspectiva, o entendimento da sintaxe e gramática das imagens contribui para a criação de um quadro de referências e a capacidade de distinguir entre diferentes produções, percebendo-as como discursos e identificando seus aspectos positivos e negativos, não apenas enquanto conteúdo, mas também no que diz respeito a sua forma. Esta proposta é especialmente importante para a desmistificação da televisão enquanto meio mais problemático e alienador, e apresenta potencial nas disputas por democratização da produção audiovisual. Como problematiza Muanis: "resta saber se a solução é jogar televisão na fogueira 
ou, para que todos sobrevivam, amplie-se a consciência, mude-se o discurso secular e democratize-se de verdade o escrever audiovisual" (p. 41).

Ainda acerca da televisão e sua qualidade, o autor reposiciona este conceito, pensado não como algo inerente aos programas, mas na circulação e nas possibilidades de leituras dos telespectadores. Produções consideradas ruins pelos críticos especializados, intelectuais, e até mesmo pelo público, podem ser bem-sucedidas na criação de debates e de experiências para os espectadores.

No campo da produção, Muanis aponta o fortalecimento da TV pública e políticas que favoreçam a regionalização e as produtoras locais como uma maneira de disseminar a pluralidade de discursos e representações de identidades diversas nas quais o público possa se reconhecer. A defesa de uma televisão aberta, que de fato seja democrática, é colocada pelo autor como uma "questão ética, mas também por sobrevivência e relevância". Essa televisão pública forte, independente, seria capaz de trazer vozes plurais para os embates discursivos contemporâneos, mas depende de repensarmos a regulamentação deste meio de comunicação no Brasil. Segundo Muanis:

Muito poucas vezes o Brasil, seu povo e os seus governantes, entenderam, valorizaram e buscaram construir uma TV de fato pública. Que ela sobreviva ao obscurantismo e possa sobreviver e se fortalecer no futuro, mas para isso precisamos vencer a nossa absoluta indigência e cinismo com relação às políticas de radiodifusão no país. (MUANIS, 2020, p. 103)

O conjunto de textos sobre documentário em suas múltiplas vertentes talvez seja o que melhor demostre a discussão sobre as transposições de fronteiras do audiovisual nos variados suportes e plataformas nos quais pode ser produzido, circulado e consumido. Como o título e a capa do livro sugerem, os textos investigam as representações possíveis por meio da linguagem audiovisual em múltiplos dispositivos. Na capa, o cachimbo reproduzido em várias telas remete à obra de René Magritte, referenciada no capítulo 11 para iniciar a discussão sobre "como materialidades diversas podem modificar e ampliar a noção de texto" (p. 204). O autor conclui que diferentes suportes ampliam as formas de leitura e possibilidades textuais de 
um produto audiovisual e abrem outras percepções e experiências, sem contradizer o suporte original da produção.

Dos textos que dizem respeito aos documentários, três se dedicam a analisar os conteúdos documentais e três estão voltados à variedade de meios e dispositivos utilizados nesta produção. O primeiro trio se insere nas discussões partindo da característica do documentário de se preocupar com "uma hipotética representação da realidade" (p. 235). O capítulo 13 analisa as estratégias empregadas na construção dos filmes Justiça (2004), de Maria Augusta Ramos, e Ônibus 174 (2002), de José Padilha, para explorar os limites da representação de acontecimentos do mundo histórico e sua relação com a ficção. Apesar de suas estratégias distintas Ramos busca o apagamento das marcas de produção e Padilha posiciona Sandro do Nascimento como narrador e usa imagens de TV na construção do filme -, Muanis avalia que ambos levam ao afastamento do espectador do fato representado pois não aprofundam ou explicam determinadas questões. No capítulo seguinte, o autor reforça os aspectos éticos e de responsabilidade do documentário em sua análise de Menino 23: Infâncias perdidas no Brasil (2016), filme que considera "felizmente pedagógico" ao confrontar a dura realidade de crianças negras e pobres no país enquanto busca resgatar do esquecimento e da invisibilidade o genocídio dos negros que é parte da nossa história. As imagens documentais do atentado às torres gêmeas do World Trade Center, em 11 de setembro de 2001, revisitadas 10 anos após o acontecimento, são o objeto de estudo do capítulo 15, que busca refletir sobre as transformações e ressignificações destas imagens com o passar do tempo e a sua relação com a memória do evento.

Os três textos seguintes do bloco sobre documentário conduzem o debate para o âmbito dos diferentes suportes e dispositivos em que a produção pode ser realizada. Esta discussão se volta, especialmente, para as relações com os meios digitais e as possibilidades que eles trazem para a linguagem audiovisual. O primeiro aponta para as possibilidades criativas de linguagem que o digital apresenta, relacionando-as com as vanguardas artísticas pela ampliação de formas e linguagens percebidas. Depois, no capítulo 17, explora o exemplo 
das projeções mapeadas e a relação entre real e virtual por meio das sobreposições imagéticas sobre edifícios e intervenções artísticas urbanas nas cidades mediadas pela tecnologia. Por fim, o capítulo 18 reflete o documentário 3.0, aquele produzido digitalmente que apresenta possibilidades dialógicas de interatividade para produtores e receptores. Nesta análise, Muanis destaca a possibilidade de um documentário-interface, que interautores possam preencher com suas experiências e enunciações, posicionando as questões éticas e de evidencia da representação, tão caras ao documentário, para o contexto da interface.

Este conjunto de textos consegue ampliar as reflexões sobre o discurso documental para além do documentário enquanto gênero do cinema. Aspectos documentais atravessam diversas produções com as quais interagimos cotidianamente, seja em conteúdo para as plataformas digitais e redes sociais, produções jornalísticas ou artísticas, na televisão, no cinema ou na internet, e no espaço urbano como um todo. O documental, como demonstrado nos capítulos desta obra, pode ser produzido a partir de várias linguagens e em múltiplos suportes.

Convergências audiovisuais: linguagens e dispositivos é uma leitura que aponta para a potência de borrarmos as fronteiras das diferentes produções audiovisuais e pensarmos nas questões transversais e interdisciplinares que permeiam as imagens e discursos midiáticos com os quais entramos em contato na contemporaneidade.

\section{Referências}

MUANIS, F. C. Convergências audiovisuais: linguagens e dispositivos. Curitiba: Appris, 2020.

RODOWICK, D. N. Audiovisual Culture and Interdisciplinary Knowledge. New Literary History, Baltimore, v. 26, n. 1, p. 111-121, 1995. 